\title{
THE LINK BETWEEN REITER'S SYNDROME AND PSORIATIC ARTHRITIS*
}

\author{
BY \\ V. WRIGHT AND WILLIAM B. REED \\ From the Rheumatism Research Unit, University Department of Clinical Medicine, Leeds, England, \\ and the Long Beach V.A. Hospital, Long Beach, California
}

Recent studies have suggested that there is an entity, psoriatic arthritis, distinct from rheumatoid arthritis (Reed and Becker, 1960; Wright, 1959). Similarly, it has been demonstrated that Reiter's syndrome has features of an inflammatory arthritis distinct from rheumatoid arthritis (Harkness, 1950; Ford, 1958; Murray, Oates, and Young, 1958; Csonka, 1960; Catterall and Perkins, 1961; Wright, 1963). We have observed, from our total experience of patients with psoriasis and arthritis, twelve who seem to form a very definite link between "psoriatic arthritis" and "Reiter's syndrome".

Although various authors have hinted at such a possibility, we have been unable to find any report in the literature of a similar series. It seemed desirable therefore to report our findings in these patients in some detail. The genito-urinary and ocular manifestations of the patients are summarized in Table I.

TABLE I

DESCRIPTION OF PATIENTS WITH SUMMARY OF GENITOURINARY INFECTION AND OCULAR LESIONS

\begin{tabular}{|c|c|c|c|c|}
\hline $\begin{array}{c}\text { Case } \\
\text { Number }\end{array}$ & Sex & $\begin{array}{c}\text { Age } \\
\text { (yrs) }\end{array}$ & Urethritis & Ocular Lesions \\
\hline $\begin{array}{r}1 \\
2 \\
3 \\
4 \\
5 \\
6 \\
7 \\
8 \\
9 \\
10 \\
11\end{array}$ & $\begin{array}{l}\mathbf{M} \\
\mathbf{M} \\
\mathbf{M} \\
\mathbf{M} \\
\mathbf{F} \\
\mathbf{M} \\
\mathbf{M} \\
\mathbf{F} \\
\mathbf{M} \\
\mathbf{M} \\
\mathbf{M}\end{array}$ & $\begin{array}{l}26 \\
33 \\
24 \\
32 \\
36 \\
31 \\
59 \\
29 \\
47 \\
26 \\
33\end{array}$ & $\begin{array}{l}\text { Multiple } \\
\text { Multiple } \\
\text { Multiple } \\
\text { Multiple } \\
\text { Twice } \\
\text { Prostatitis } \\
\text { Once } \\
\text { Once } \\
\text { Prostatitis } \\
\text { Once } \\
\text { Chronic }\end{array}$ & $\begin{array}{l}\text { Iritis } \\
\text { Conjunctivitis } \\
\text { Iritis } \\
\text { Iritis } \\
\text { Conjunctivitis } \\
\text { Conjunctivitis and } \\
\text { Iritis }\end{array}$ \\
\hline
\end{tabular}

Case 1, a 26-year-old man, was admitted to hospital with an exacerbation of arthritis. He had developed polyarthritis 5 years previously with involvement of the spine indicating ankylosing spondylitis. He had episodes of urethritis 3 years and 18 months before. No bacteriological diagnosis was made on these occasions, but it

* Paper read to the Heberden Society on December 7, 1963. appeared that both attacks responded to penicillin. 11 months previously, after a $2 \frac{1}{2}$-year remission of arthritis, he had an acute exacerbation. 10 days later a rash appeared on the abdominal wall and spread to involve the feet, knees, genitalia, anterior aspect of the thighs, chest, and back between the scapulae (Figs 1 and 2). The patient had lost $30 \mathrm{lb}$. in the month before admission.

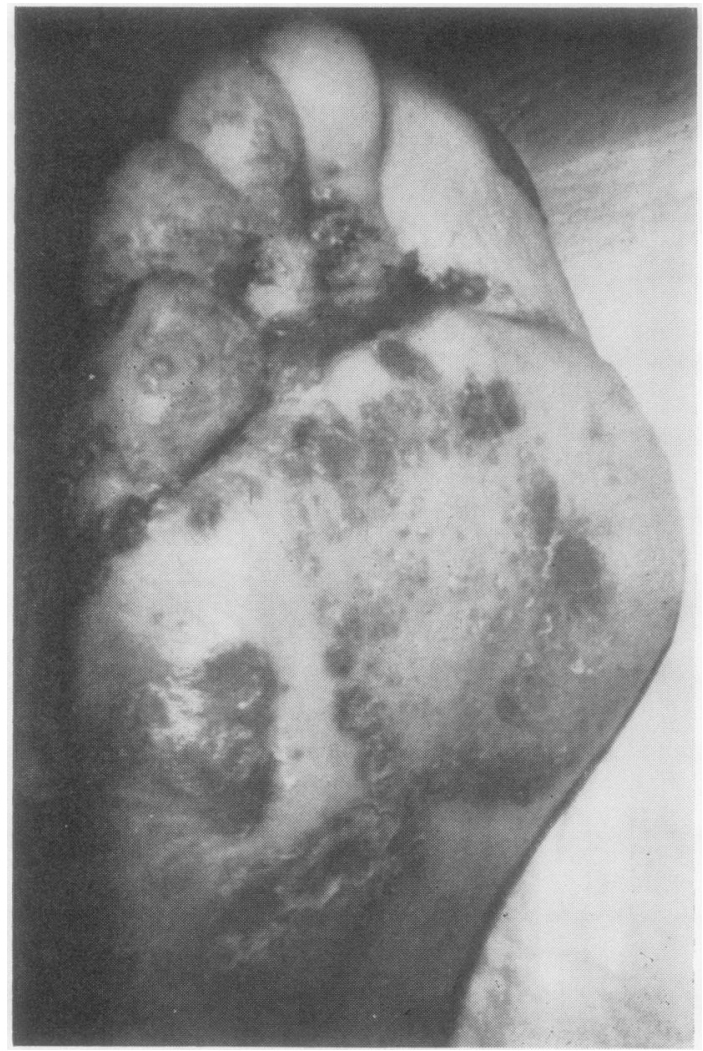

Fig. 1.-Case 1, showing keratodermia blennorrhagica on sole. 


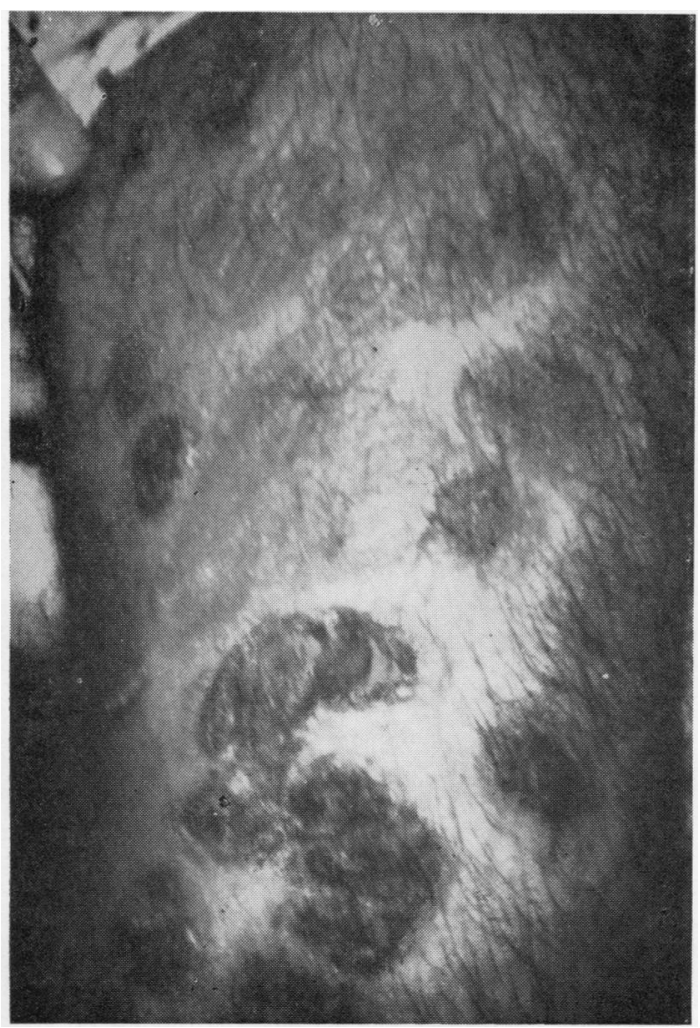

Fig. 2.-Case 1, showing skin lesions on leg below the knee.

Examination.-There were skin lesions with a rupioid scale, which were most extensive on the feet, toes, and fingers (Fig. 3).

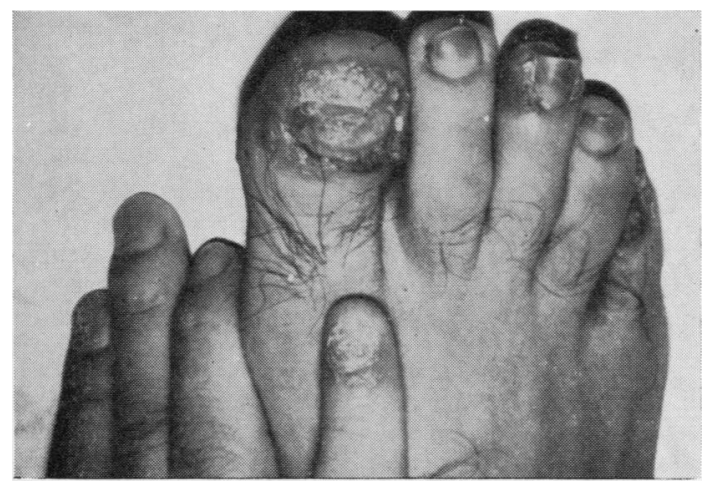

Fig. 3.-Case 1, showing nail changes and periungual skin lesions on fingers and toes.

He was treated with large doses of prednisolone (100 mg. four times daily initially). This was gradually reduced and was discontinued 2 months later. There- upon he had an exacerbation of arthritis and skin lesions, necessitating re-admission to hospital a month later. The joints were swollen and painful, and the skin was covered with symmetrically-distributed nummular plaques which had annular, arciform, circinate borders, and erythematous scaling surfaces. There was a tendency towards central clearing of the lesions. Typical psoriatic lesions were present. In the next 6 months he developed generalized exfoliative erythroderma on two separate occasions with partial remission each time.

Ancillary investigations showed a white cell count ranging from 12,500 to 23,000 with a normal differential count. $\mathrm{Hb}$ on the second admission had dropped to $8.6 \mathrm{~g}$. per cent. and he was transfused with two pints of blood. The erythrocyte sedimentation rate remained constantly elevated during the period of observation, ranging from 44 to $64 \mathrm{~mm}$. in the first hour. The latex slide test was negative, serum albumin $2.5 \mathrm{~g}$. per cent. serum globulin $5 \cdot 1$ g. per cent. Electrophoresis revealed increased gamma globulin. Serum uric acid was $7 \cdot 7$, $7 \cdot 2$, and $6 \cdot 8 \mathrm{mg}$. per cent. on three separate occasions. $X$ rays of the sacro-iliac joints showed sclerosis and erosion of the joints bilaterally; those of the lumbar spine were normal; those of the feet and hands showed juxtaarticular osteoporosis without erosion or loss of joint space.

Comment.-This man appeared to have Reiter's syndrome manifested by arthritis, spondylitis, urethritis, and keratodermia blennorrhagica. While lesions of keratodermia blennorrhagica were present, lesions of psoriasis developed elsewhere. The use of corticosteroids and their withdrawal led to a severe exacerbation of the psoriasis which did not respond again to their use. The persistently raised serum uric acid is of interest in view of reports of this in cases of psoriasis (Schamberg and Brown, 1923; Herrmann, 1930; Kaplan and Klatskin, 1960; Baumann and Jillson, 1961).

Case 2, a 33-year-old man, developed arthritis at the age of 15 . This subsided for 9 years; then he had an acute polyarthritis involving nearly every joint of the body except the spine. 3 years later he developed keratodermia blennorrhagica affecting the nails, soles of the feet, penis, elbows, and groins (Figs 4 and 5 , overleaf).

$\mathrm{He}$ had lesions of psoriasis on the knees, scalp, and dorsum of the hands. At this time he had urethritis which was said to be gonococcal, but no bacterial examination was done. Since then he has had multiple attacks of abacterial urethritis.

Investigations.-Biopsies were taken from the left foot, leg, and penis. Those from the foot and leg showed chronic inflammatory change and that from the penis a psoriasiform reaction.

He later developed bilateral iritis.

At that time an aortic diastolic murmur and tachycardia was noted. An electrocardiograph showed left ventricular preponderance. The latex slide test was 


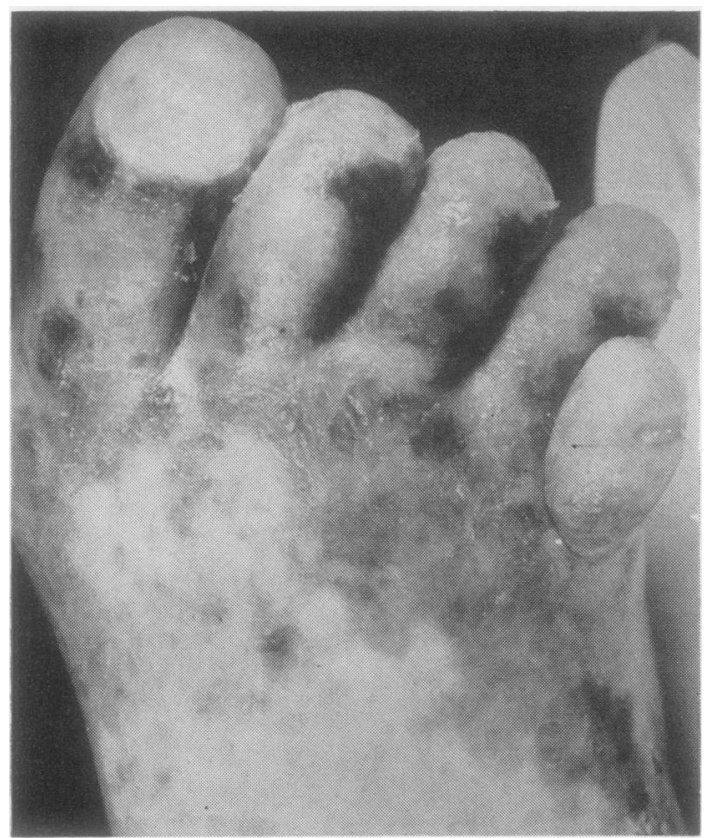

Fig. 4.-Case 2, showing skin and nail changes on foot.

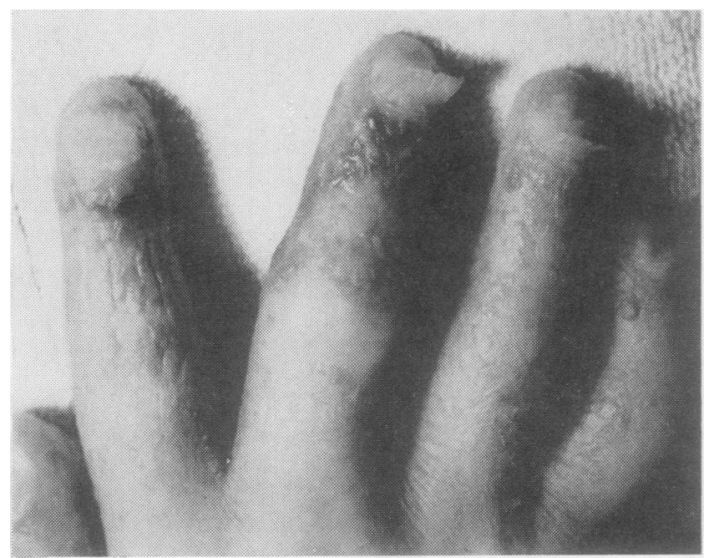

Fig. 5.-Case 2, showing skin and nail changes on fingers.

negative and there were no lupus erythematosus cells in the peripheral blood. $X$ rays of the hands and feet showed marked deformity with loss of joint space and major erosions.

Treatment with cortisone did not help. Chloroquine caused an exacerbation of the condition. The deformity of the legs became so severe that at the age of 30 both were amputated.

Comment.-A most interesting example of Reiter's syndrome displaying arthritis, urethritis, iritis, and keratodermia blennorrhagica, with the development of an aortic lesion during the course of the disease. Psoriatic lesions were present at the same time as those of keratodermia blennorrhagica.

Case 3, a 24-year-old man, developed arthritis at the age of 21 involving the hands, hips, and ankles. This was preceded by an abacterial urethral discharge which has been intermittent since that time. 6 months later he developed keratodermia blennorrhagica of the feet, circinate balanitis, and definite psoriatic lesions in the scalp. The skin cleared and the arthritis has been intermittently active since, involving knees, hips, ankles, and cervical spine. During the active phase he had intermittent pyrexia to $101^{\circ} \mathrm{F}$. and tachycardia.

Ancillary investigations showed a negative latex slide test, and no lupus erythematosus cells in the peripheral blood. $X$ rays of the sacro-iliac joints showed sclerosis.

Comment.-This man had Reiter's syndrome with abacterial urethritis, arthritis, circinate balanitis, and keratodermia blennorrhagica. No ocular lesions were observed. When lesions of keratodermia blennorrhagica appeared, definite psoriasis developed on the scalp.

Case 4, a 32-year-old man, had a history of intermittent arthritis involving the left knee, wrists, and lumbar spine for 10 years. Over this period he had intermittent urethritis, which was called gonorrhoea, but no organisms could be cultured from the urethral discharge, and it had not cleared with penicillin. 5 years after the start of the arthritis he developed psoriasis of guttate type. On one occasion an exacerbation was caused by chloroquine. 5 years after the onset of the skin lesions, keratodermia blennorrhagica appeared on the soles and palms. Biopsies of these lesions showed acanthosis, absence of stratum granulosum, parakeratosis, and intercellular oedema with migration of leucocytes from the corium collecting into foci beneath the stratum corneum (abscesses of Munro). There was no conjunctivitis.

$X$ rays of the sacro-iliac joints showed ankylosis. The latex slide test was negative and there were no lupus erythematosus cells in the peripheral blood.

Comment.-This case was diagnosed as one of Reiter's syndrome on the basis of typical arthritis, abacterial urethritis, sacro-iliac joint involvement, and a negative latex slide test. During the course of his illness he developed classical psoriasis and 5 years later the lesions of keratodermia blennorrhagica.

Case 5, a woman married to a long-distance lorry driver, was first seen in 1954 at the age of 27 when she developed skin lesions of the feet, which became "all crusted over". At the same time her nails became severely involved and she had a vaginal discharge; 4 months later her legs became stiff, principally in the ankles and knees. She 
felt ill at this time and was admitted to hospital. While an in-patient she developed psoriasis of the scalp and back and the arthritis became widespread with painful swelling of every joint of the upper limbs, including the distal interphalangeal joints. The vaginal discharge became worse and she developed a purulent conjunctivitis. After 6 weeks in hospital, she began to recover and she was discharged after 13 weeks.

6 months later arthritis recurred in the ankles, knees, hips, shoulders, and fingers, and the skin rash reappeared. Scattered red papular lesions were noted on the trunk and back, with a pustular eruption of the feet and thickened yellow nails. She had scalding micturition and catheter specimens of urine grew coliform organisms; a film of the urinary deposit showed squamous cells only.

All these symptoms then subsided and she was perrectly well for 7 years, when she developed pain around the chest and back, followed by pain and swelling of the metacarpo-phalangeal joints of the left hand. 2 days later she had acute arthritis of the wrists and right knee. At this stage the vaginal discharge became profuse, and she developed conjunctivitis and striking yellow discolouration and thickening of all the finger nails (Fig. 6). Her youngest sister has recently developed psoriasis, but there is no other relevant family history.

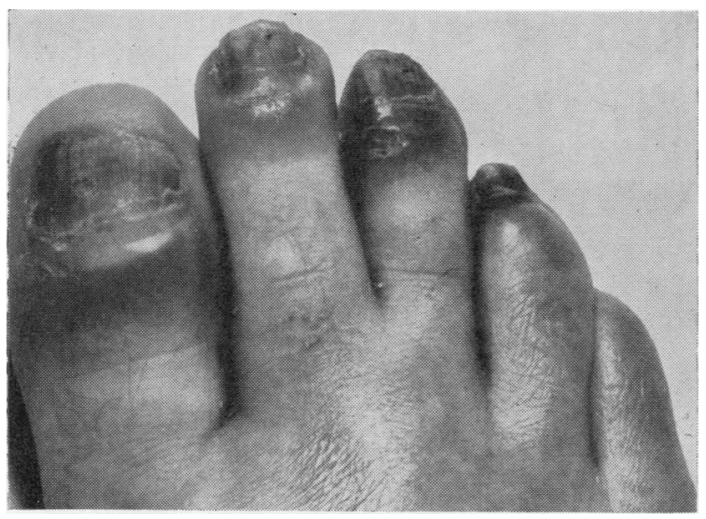

Fig. 6.- Case 5, showing nail changes and pustular lesions at base of nails on toes.

At the base of the nails there were lakes of pus; sparse skin lesions were present on the back and one on the forehead. Biopsy of the skin of the back showed a thin keratotic and parakeratotic layer overlying the epidermis, which displayed acanthosis in limited areas. Two irregular lacunae were present in the epidermis. Beneath these areas some upper dermal lymphocytic infiltration and elsewhere at the same level slight focal lymphocytic infiltration.

Comment.-This was an example of Reiter's syndrome in a woman, a considerable rarity. The patient showed the classical triad of urethritis, arthritis, and conjunctivitis, and she also developed keratodermia blennorrhagica, with simultaneous psoriasis of the scalp.
Case 6, a 31-year-old man, first had psoriasis of the scalp at the age of 17 . This later became generalized. At the age of 23 he developed arthritis of the left knee and later of the right knee. This subsided in 7 weeks. At that time there was little change in the psoriasis except that he developed lesions on the soles of the feet. The arthritis recurred in the left knee 4 years later but settled in 4 weeks. At the age of 30 he developed pain in the metatarso-phalangeal joints, and in many other joints including the distal interphalangeal joints of the fingers and toes. He had pain around the tendoAchilles. Nail changes began 3 years after the onset of arthritis. There was no relevant family history. He denied genito-urinary infection.

Examination.-There was psoriasis vulgaris of the scalp, trunk and limbs, and lesions of keratodermia blennorrhagica on the soles. There were pronounced dyskeratotic lesions of the finger and toe nails. Active arthritis affected the distal joints of the fingers, left elbow, knees, ankles, metatarso-phalangeal joints, and toes. Rectal examination revealed a bulky, tender prostate, especially in the right lobe. No fluid could be obtained by prostatic massage on two occasions, but the appearance of the gland suggested chronic prostatitis.

Blood tests showed $\mathrm{Hb} 90$ per cent., erythrocyte sedimentation rate $42 \mathrm{~mm}$. first hour, white blood count 12,200 , no lupus erythematosus cells, differential agglutination test negative, serum uric acid $5.6 \mathrm{mg}$. per cent.

$X$ rays of the hands showed minor marginal erosions of the distal interphalangeal joints. In the feet there were erosions of the metatarso-phalangeal joints and destruction of some terminal phalanges. The sacro-iliac joints were normal.

Comment.-This patient had psoriatic arthritis involving the distal interphalangeal joints. In addition he had lesions on the soles indistinguishable from those of keratodermia blennorrhagica. Although no history of genito-urinary infection was obtained, examination of the prostate suggested chronic prostatitis.

Case 7, a 59-year-old man, was kept under observation for 5 years. At the age of 39 he had developed stiffness of the back after an episode of urethritis. Later he developed pain and swelling of the right second toe, shoulder, elbow, metacarpo-phalangeal and proximal interphalangeal joints, knee, ankle, and metatarsophalangeal joints. At the age of 51 psoriasis appeared on the hands and elbows, which necessitated admission to hospital. 3 years later it was noted that he had keratodermia blennorrhagica involving the soles and palms, and psoriasis over the trunk and limbs. Since that time he has had 6 attacks of iritis with subsequent blindness in the right eye.

Recent Examination.-The right shoulder was frozen, wrist movement was limited, and there were mild deformities of elbows, metacarpo-phalangeal and proximal interphalangeal joints of some fingers, right knee, ankles, 
and metatarso-phalangeal joints. He also had a bamtoo spine.

The differential agglutination test was persistently negative. The erythrocyte sedimentation rate which was $52 \mathrm{~mm}$. in the first hour when he was first seen, has now fallen to $12 \mathrm{~mm}$. Hb has increased from 70 to 90 per cent. Serum albumin $4 \cdot 2$ and serum globulin $2 \cdot 6$ g. per cent.

$X$ rays showed ankylosis of the sacro-iliac joints, major erosions and deformity of the carpus, metacarpophalangeal, and proximal interphalangeal joints of the fingers, minor erosions in the tarsus and metatarsophalangeal joints, and erosion of the knee joints with marked patellar involvement.

Comment.-In this man Reiter's syndrome produced a picture similar to that of ankylosing spondylitis with peripheral joint involvement. He has since developed psoriasis and in one phase the lesions of keratodermia blennorrhagica also appeared.

Case 8, a 29-year-old woman, had started with psoriasis of the skin and nails, and arthritis involving the knees and ankles 2 years previously, after separation from her hustand. A vaginal discharge was present, she had scalding micturition, and also developed iritis at this time.

The severity of the skin lesions required admission to hospital, where keratodermia blennorrhagica of the soles and typical psoriatic lesions on the trunk and scalp were noted. The polyarthritis then became widespread, involving the shoulders, wrists, metacarpophalangeal joints, temporo-mandibular joints, and toes. She was treated with adrenocorticotrophin and within a few months all lesions cleared.

A year later the discoloration and hyperkeratosis of the nails of fingers and toes recurred. At this time there was no objective evidence of arthritis, although she states that she had some pain in the right shoulder and knee. The skin lesions had completely disappeared.

Investigations.-The differential agglutination test was negative, and $x$ rays of the hands, feet, and sacro-iliac joints were normal.

Comment.-An interesting example of a woman with the triad of Reiter's syndrome with lesions of keratodermia blennorrhagica, and simultaneously typical lesions of psoriasis vulgaris on the scalp and trunk.

Case 9, a 47-year-old man, had had an exudative dermatitis of the fingers since his teens. At the age of 41 he developed psoriasis of the arms which cleared with treatment, but recurred 4 years later while he was in hospital for the treatment of arthritis involving the cervical spine, right shoulder, elbow, wrist, and fingers. This spread to involve the majority of the joints and the heels. 2 years later the nails were severely involved and since then he has had a number of episodes of keratodermia blennorrhagica affecting the soles. Skin biopsy showed hyperkeratosis with some parakeratosis. The epidermis was acanthotic with slightly elongated rete pegs some of which had a clubbed appearance. There was also spongiosis and a diffuse infiltrate of inflammatory cells in the epidermis. The dermis contained a mixed inflammatory cell exudate. There was no subepidermal vesiculation. He denied genito-urinary infection, but prostatic massage produced numerous pus cells.

Recent Examination.-He had frozen shoulders, mild flexion deformities of the elbows, limitation of movement of the wrists and right ankle, tender subluxated metatarso-phalangeal joints, and limitation of movement of the cervical and lumbar regions of the spine. To control the activity of the arthritis prednisolone $5 \mathrm{mg}$. three times daily was given. Recently a cataract thought to be related to steroid medication developed.

The differential agglutination test and latex slide tests were persistently negative. The erythrocyte sedimentation rate at times has been high $(116 \mathrm{~mm}$. in the first hour). $\quad X$ rays showed minor erosions around the base of the metacarpals, considerable erosion and subluxation of the metatarso-phalangeal joints and evidence of periostitis at the insertion of the plantar fascia in the os calcis on both sides. The right sacro-iliac joint showed sclerosis around the margins.

Comment.-An example of psoriatic arthritis with involvement of the sacro-iliac joints. Keratodermia blennorrhagica developed during the course of the disease and there was evidence of chronic prostatitis.

Case 10, a 25-year-old man, had developed lymphogranuloma venereum 6 years previously. He then had urethritis, and later had psoriasis of the scalp with numerous episodes of generalized erythrodermia. The skin lesions proved resistant to treatment and on one occasion the lesions of keratodermia blennorrhagica appeared on the soles. In the previous 12 months he had been admitted to hospital five times with erythrodermic psoriasis which cleared rapidly with topical triamcinolone under occlusive dressings.

At the age of 24 arthritis started in the ankle and later involved other joints, including the distal interphalangeal joints, toes, and back. Control of the skin and joint lesions required oral triamcinolone $4 \mathrm{mg}$. twice daily for 12 months.

Investigations.-The differential agglutination test was persistently negative. $X$ rays of the hands showed minor erosion of a proximal interphalangeal joint of the left carpus. The feet were normal. The sacro-iliac joints showed marked sclerosis and erosion. For 12 months he had numerous episodes of conjunctivitis. Prostatic massage showed evidence of chronic prostatitis.

Comment.-This man with the triad of Reiter's syndrome presented features of psoriatic arthritis with distal joint involvement. The pustular lesions of the feet suggest a link between Reiter's syndrome and psoriatic arthritis.

Case 11, a 33-year-old man, was under observation for 10 years until his death at the age of 43 . He was born with congenital interstitial keratitis and received weekly 
injections for 4 years between the ages of 8 and 12. At the age of 16 he had rheumatic fever.

He had no further illnesses until the age of 33 when he presented with a urethral discharge which had been present for 6 weeks and in which scanty gonococci were found. He then developed pain and swelling in the toes and left knee. He was given a course of penicillin which partially cleared the discharge.

Examination.-A soft systolic murmur was present at the apex and a harsh systolic murmur at the base of the heart. He was febrile at this time with a temperature of $100^{\circ} \mathrm{F}$. A month later he developed splenomegaly and a little hyperkeratosis of the finger and toe nails. Blood culture was sterile on two occasions. Hb 70 per cent., white cell count 8,200 , with a normal differential count.

Progress.-He was given a further course of penicillin 5,000 units 3-hourly. During this second course of treatment a skin eruption broke out and spread rapidly from the digits to the limbs. He was seriously ill, toxic, and wasted, and the arthritis became widespread. Skin lesions characteristic of keratodermia blennorrhagica were present on the hands, feet, and trunk. There were thick, rupioid crusts particularly marked on the anterior portion of the soles. Arthritis was present in the metacarpo-phalangeal joints, wrists, elbows, knees, and ankles, with ulnar deviation of the fingers and considerable muscle wasting. A course of intravenous typhoid vaccine was given and his condition improved considerably, so that he was discharged with no skin lesions 5 months later. A skin biopsy at this time was compatible with a late, almost completely regressed lesion of keratodermia blennorrhagica. Section of the toe nail showed thickening with underlying marked hyperkeratosis and parakeratosis of the nail bed.

4 years later he felt ill and noticed irritation at the end of the penis with a white discharge. At the same time he developed a mild conjunctivitis and a shaggy left iris was noted which appeared to indicate longstanding disease. There was swelling, heat, and tenderness of the elbows, wrists, and shoulder. The knees showed effusion without other evidence of activity. He then developed rupioid ulcerative lesions of the feet and legs.

Investigations.-At this time $\mathrm{Hb}$ was 61 per cent., erythrocyte sedimentation rate $61 \mathrm{~mm}$. first hour, serum albumin $1 \cdot 25 \mathrm{~g}$. per cent. and serum globulin 4.05 g. per cent. A swab from the pustular lesions of the fingers grew no organisms. The serological test for syphilis was persistently negative and lumbar puncture showed a normal cerebrospinal fluid.

$X$ rays showed increased markings throughout the lung fields, and definite osteoporosis in the right carpus with some loss of joint space.

Progress.-Joint pain continued unabated for 2 months, but gradually improved with rest in bed. Low grade pyrexia was present, which did not respond to chloromycetin, aureomycin, penicillin, or sulphapyridine. The skin condition became progressively more florid. However, at the time of a further course of sulphapyridine, a remarkable and rapid regression of the skin lesions occurred, so that 5 months after admission he was discharged with no lesions at all. He remained well for 5 months but then developed arthritis of the hands, wrists, elbows, shoulders, and knees, while brown hyperkeratotic pigmented lesions appeared around both heels and later spread to the soles of the feet. These gradually regressed and the arthritis improved.

The patient had no further trouble for 2 years, but was then re-admitted with paranoia, which remitted spontaneously.

A year later he complained of low back pain radiating into the right thigh, which had come on gradually over the previous 6 months, and was aggravated by coughing.

Examination.-There was no deformity of the spine, although flexion was restricted and painful. $X$ rays of the sacro-iliac joints showed sclerosis.

Terminal Illness. - Later the same year, he was admitted to hospital with a recurrence of severe pain in the right foot accompanied by an exacerbation of the skin lesions on the trunk and arms. He was given a course of phenylbutazone $300 \mathrm{mg}$. daily, but after 15 days developed considerable fluid retention and congestive heart failure. The drug was stopped and his condition improved considerably, but skin lesions were still extensive. He was given cortisone $25 \mathrm{mg}$. twice daily, but within 48 hours there was definite retention of fluid. He had an attack of acute pulmonary oedema and was very ill for a short period. The drug was stopped and he was given a short course of sulphapyridine, but without benefit on this occasion. Prednisolone $20 \mathrm{mg}$. daily was then given. There was no fluid retention, and the dose was increased to $40 \mathrm{mg}$. daily, when he made a dramatic response.

However, 2 months later there was an exacerbation of the arthritis and skin lesions, which necessitated re-admission to hospital. He improved satisfactorily and was discharged on prednisolone $50 \mathrm{mg}$. daily. 2 months later he was re-admitted with a further exacerbation of skin lesions and some fluid retention. The corticosteroids were reduced, but this was followed by a drop in blood pressure and signs of adrenal insufficiency. A course of ACTH gel $\mathbf{4 0}$ units daily produced improvement, but left-sided heart failure suddenly developed and he died shortly afterwards at the age of 43 .

Post mortem Examination.-There were extensive skin lesions of keratodermia blennorrhagica with marked nail changes. The pleural cavity contained four pints of clear fluid on the left and one pint on the right. Dense adhesions bound the left lung to the mediastinum and chest wall. The pericardium was normal. The heart was enlarged mainly because of left ventricular hypertrophy. Both mitral and aortic valves were stenosed and would admit one finger only with difficulty. The valve cusps were adherent and fibrotic. The liver was firm and showed chronic venous congestion. 
The right knee joint contained no fluid, but the synovial membrane was thickened.

Histological examination of the skin showed features common to keratodermia blennorrhagica and pustular psoriasis with a considerable amount of keratosis, parakeratosis, acanthosis, and marked intercellular oedema, with numerous leucocytes producing abscesses of Munro.

Tissue from the capsule of the sacro-iliac joint showed a pronounced inflammatory reaction with polymorph leucocytes and lymphocytes, but it was non-specific in character.

A section through the distal part of a finger showed dyskeratosis of the nail with underlying changes similar to those in the skin.

Comment.-An interesting example of a man who was followed for 10 years from the beginning of his illness to his death, when autopsy examination was permitted. He began with a classical Reiter's syndrome and during the course of his illness developed typical psoriatic lesions on the trunk.

\section{Discussion}

Reiter's syndrome and psoriatic arthritis have clinical similarities in certain patients. When cutaneous lesions appear on the palms, soles, and penis and nail changes develop in both syndromes, the relationship between the diseases requires examination. The present series of patients seems to represent a very definite link between the two conditions.

\section{Cutaneous Lesions}

The most distinctive skin eruption in Reiter's syndrome is keratodermia blennorrhagica, consisting of hard parakeratotic nodules and soft limpet-like parakeratotic patches. Superficial circinate lesions of the glans penis are also found. The presence of scaling depends greatly upon the acuteness of the lesion and whether circumcision is present. The cutaneous lesions do not result from the presence of a urethral discharge since they persist or develop after the urethritis has cleared. Cutaneous involvement in recurrent attacks is most commonly limited to the glans penis (Weinberger, Ropes, Kulka, and Bauer, 1962). The lesions of the soles and palms are clinically indistinguishable from those seen in pustular psoriasis (Engleman, 1960). There is no difference between the lesions of keratodermia blennorrhagica and rupioid psoriasis when they occur on the body and, in reviewing many cases of keratodermia blennorrhagica in the literature, it is impossible to distinguish them from rupioid psoriasis (Lever and Crawford, 1944; Naegeli, 1938; Kuske, 1939; Lojander, 1927; Löhe and Rosenfeld, 1929). Our patients are particularly interesting in that classical psoriatic lesions were actually present at the same time as lesions of keratodermia blennorrhagica. Two patients developed widespread erythrodermic psoriasis.

The second striking feature is the temporal relationship between the appearance of keratodermia and psoriasis in these patients. In six patients both occurred at the onset of skin changes, in five patients keratodermia occurred as an apparent manifestation of psoriasis during periods varying from 3 to 6 years after the onset of skin disease, and in one patient typical psoriatic lesions occurred 7 years after recurrent keratodermia blennorrhagica had first manifested itself. It is of interest that the patient of Löhe and Rosenfeld (1929) with keratodermia blennorrhagica subsequently developed psoriasis vulgaris.

With a relatively common disease such as psoriasis, it could be argued that some patients with Reiter's syndrome are liable to develop psoriasis coincidentally. This is true and may well be illustrated by the following case:

Case 12, a 47-year-old miner, developed a painful swelling of the right knee after an attack of non-specific urethritis. The right ankle then became painful and swollen and the back became painful. Over a period of months he became symptom-free and the only residuum was sclerosis and erosion of the right sacro-iliac joint seen radiologically.

12 months later he fractured the left leg at work and soon after recovery from this had a haematemesishe was on no drugs at the time and had no dyspepsia before or since. A barium meal showed appearances suggestive of a duodenal ulcer. Soon after this psoriatic lesions appeared on the scalp and a few lesions on the back and abdomen. There was no recurrence of arthritis or urethritis at this time and observation for a year has shown no abnormality apart from psoriasis.

In this patient the development of Reiter's syndrome and psoriasis appear to be unconnected. The temporal relationship in Cases 1 to 11 , however, suggests that the association is not fortuitous, but that an intimate connexion exists. There appears in these patients to be no clear-cut demarcation between the syndromes.

Acute psoriatic arthritis may develop with exudative or pustular lesions on the palms, soles, and penis. Scalp lesions are usually present in addition. 
It is of interest that we have already shown that pustular psoriasis is significantly more common in those patients with psoriatic arthritis who have severe joint disease than in those with uncomplicated psoriasis (Wright, 1959).

The histopathological appearance of the cutaneous lesions of psoriatic arthritis and keratodermia blennorrhagica were indistinguishable in the seven biopsies from our cases. The appearance depends on the age, location, and treatment of the lesions. Our findings confirm those of Weinberger and others (1962), who noted a similar subacute inflammatory process which was largely confined to the stratified squamous epithelium and upper dermis. The striking gross differences between the plantar, penile, and mucosal lesions were due to variations in the degrees of keratosis-this was heaviest over the sole, moderately heavy over the circumcised penis, and essentially absent over moist penile lesions. As with psoriasis the epidermis showed acanthosis with elongation of the rete pegs and thinning of the suprapapillary portions of the stratum Malpighii. There was usually loss of the stratum granulosum, and Munro abscesses (collections of neutrophiles in the stratum corneum) were found in both psoriatic arthritis and keratodermia blennorrhagica. In the more acute inflammatory phase of psoriasis, Munro abscesses were as frequent as those seen with keratodermia blennorrhagica.

\section{Nail Changes}

Involvement of nails, although sometimes dramatic in Reiter's syndrome, is not distinctive, since heaping up of keratotic material under the distal end of the nail plate may occur in psoriasis with or without arthritis. In psoriatic arthritis there is a high incidence of nail involvement and this is a striking feature in those in whom the distal interphalangeal joints are involved (Wright, 1959; Reed and Becker, 1960).

\section{Ocular Changes}

Conjunctivitis is, of course, part of the classical triad of Reiter's syndrome. It may, however, be so mild as to escape the patient's notice (Paronen, 1948 ) or many years may intervene before it develops (Csonka, 1958). Harkness (1950), who strongly holds the view that Reiter's syndrome is in no way linked with psoriatic arthritis, cites the absence of ocular lesions in psoriatic arthritis as powerful evidence for his contention, stating, "I have never seen a case of (psoriatic arthritis) with inflammation of the eyes or with urethritis." It is, therefore, of particular interest that six of our eleven patients had ocular inflammation.

\section{Arthritis}

The spectrum of articular involvement in Reiter's syndrome is broad, varying from an acute monarticular arthritis, subsiding within 3 or 4 days, to chronic, progressive polyarthritis with prolonged activity and considerable joint damage. Isolated synovial biopsies taken from cases of the chronic progressive type indicate that disease activity continues (Ropes and Bauer, 1953). This type presents a picture which cannot be distinguished from that of destructive psoriatic arthritis. In both groups tests for rheumatoid factor in the serum are negative, and radiological changes in the sacro-iliac joints are common, shown by narrowing, erosion, subluxation, and fusion of the peripheral joints (Table II).

TABle II

$X$-RAY CHANGES IN THE SACRO-ILIAC JOINTS, HANDS, AND FEET

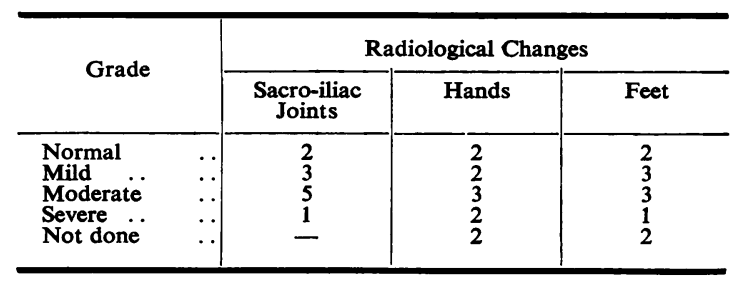

In a radiographic study of 121 unselected patients with psoriatic arthritis, erosion of the sacro-iliac joints was found in 19 per cent., but the incidence of sacro-iliitis was much higher in the severer form of arthritis occasionally seen in this syndrome (Wright, 1961). Figures for the incidence of sacro-iliac involvement in Reiter's syndrome vary from 20 to 50 per cent. The high incidence ( 81 per cent.) of sacro-iliitis in this present series is therefore of considerable importance.

Circumstantial evidence indicates that Reiter's syndrome is caused by an infective agent, probably a virus, even though certain features may be the manifestation of a sensitivity reaction-a situation analogous to the relationship between rheumatic fever and beta-haemolytic streptococcal infection. The influence of infection on the course of psoriasis is well illustrated by the exacerbation of skin lesions provoked by streptococcal infections, particularly in children, and it is not unlikely that a virus may be similarly implicated. The importance, therefore, of 
demonstrating the link between certain forms of Reiter's syndrome and psoriatic arthritis lies in the fact that the characterization of the causative organism may be valuable in the prevention and treatment of both types of arthritis.

\section{Summary}

From our total experience of patients with psoriatic arthritis, twelve cases have been described in detail. One of these appeared to exemplify the coincidence of psoriasis and Reiter's syndrome. The other eleven demonstrated an intimate link between "psoriatic arthritis" and "Reiter's syndrome". Patients developed lesions of keratodermia blennorrhagica and manifestations of psoriasis elsewhere on the body. The temporal relationship suggested that this was due to something more than chance. The similarity of certain forms of psoriasis and keratodermia blennorrhagica has been demonstrated both clinically and histologically. The high incidence of ocular manifestations and sacro-iliac joint involvement emphasizes the lack of demarcation between Reiter's syndrome and psoriatic arthritis. The significance of these observations from an aetiological point of view has been discussed.

\section{REFERENCES}

Baumann, R. R., and Jillson, O. F. (1961). J. invest. Derm., 36, 105.

Catterall, R. D., and Perkins, E. S. (1961). Brit. J. Ophthal., 45, 109.

Csonka, G. W. (1958). Brit. med. J., 1, 1088.

- (1960). Arthr. and Rheum., 3, 164.

Engleman, E. P. (1960). In "Arthritis", ed. J. L. Hollander, 6th ed., pp. 942-58. Kimpton, London.

Ford, D. K. (1958). Bull. rheum. Dis., 8, 159.

Harkness, A. H. (1950). In "Non-gonococcal Urethritis." pp. 99-145. Livingstone, Edinburgh.

Herrmann, F. (1930). Arch. Derm. Syph. (Berl.), 161, 114.

Kaplan, H., and Klatskin, G. (1960). Yale J. Biol. Med., $32,335$.

Kuske, H. (1939). Arch. Derm. Syph. (Berl.), 179, 58.

Lever, W. F., and Crawford, G. M. (1944). Arch. Derm. Syph. (Chicago), 49, 389.

Löhe, H., and Rosenfeld, H. (1929). Derm. Z., 55, 355.

Lojander, W. (1927). Acta derm.-venereol. (Stockh.), 8, 227.

Murray, R. S., Oates, J. K., and Young, A. C. (1958). J. Fac. Radiol. (Lond.), 9, 37.

Naegeli, O. (1938). Schweiz. med. Wschr., 19, 794.

Paronen, I. (1948). Acta med. scand., Suppl. 212.

Reed, W. B., and Becker, S. W. (1960). A.M.A. Arch. Derm., 81, 577.
Ropes, M. W., and Bauer, W. (1953). In "Synovial Fluid Changes in Joint Disease", p. 110. Harvard University Press, Cambridge, Mass.

Schamberg, J. F., and Brown, H. (1923). Arch. intern. Med., 32, 203.

Weinberger, H. J., Ropes, M. W., Kulka, J. P., and Bauer, W. (1962). Medicine (Baltimore), 41, 35.

Wright, V. (1959). Amer. J. Med., 27, 454.

- (1961). Ann. rheum. Dis., 20, 123.

(1963). Ibid., 22, 77.

\section{DISCUSSION}

DR. J. S. LAWRENCE (Manchester): I am most interested in Dr. Wright's findings. I am at present carrying out a family survey of patients with Reiter's disease and, although we have so far only examined 81 relatives, of the 37 males, three have psoriasis and two have spondylitis. This is nothing that the statisticians would get excited about, but if this trend continues it means that psoriasis is about six times as common in this group as in the general population.

DR. J. T. Scotr (Hammersmith): Does this mean that we should be looking for evidence of urethral infection in our patients with psoriatic arthritis? Dr. Wright mentioned chronic prostatitis in some of his patients. I wonder if he would define this.

DR. WRIGHT: Two of these patients had chronic prostatitis. On rectal examination there was a bulky, irregular, tender gland and prostatic massage produced numerous pus cells in clumps. This was confirmed by our venereologist, Dr. R. D. Catterall. We are at present investigating the incidence of chronic prostatitis in psoriatic arthritis.

DR. A. J. Popert (Manchester): I was interested in Dr. Wright's paper, but I remain unconvinced that these two conditions are related.

I should be interested to know the frequency of mucosal lesions in psoriasis which is uncomplicated by anything other than the skin lesions? Also the incidence of cardiac lesions and aortitis in the psoriasis by itself?

I should also like to know how often psoriasis is venereally acquired? In our experience Reiter's is nearly always a venereal one.

DR. Wright: Mucosal lesions are uncommon in simple psoriatic arthritis. Aortic lesions were present in two of these eleven patients and we have found aortic lesions in four patients with psoriatic arthritis. In patients with uncomplicated psoriasis we found no valvular disease of the heart. I do not believe that psoriasis is venereally acquired, although in a patient who is predisposed to psoriasis it may be precipitated by a venereal infection. I am not saying that psoriatic arthritis and Reiter's disease are always one and the same thing, but I am suggesting that in these eleven patients the similarity is such, and the link so intimate, that in this particular group it appears to be more than a chance association, the exact significance of which I do not know. 
Prof. E. G. L. Bywaters (Hammersmith): Just to get Dr. Wright to come out in the open and clarify this last point-he thinks that there are two separate diseases? Is this correct? But occasionally there is a tendency for the manifestations of both to occur in the same patient?

DR. Wright: I will try and give as unequivocal an answer as I can! We appear to have here a spectrum and at either end the two diseases seem to be distinct, but we have in the middle this group of patients in whom the various manifestations are so difficult to distinguish that for me it is quite impossible to separate them.

DR. R. M. Mason (London Hospital): The trouble is that we have not yet identified the organism.

Dr. J. FrançoIs (Aix-les-Bains): Dr. Wright spoke about streptococcal infection being associated with a flare-up of psoriasis. Others have talked about the same phenomenon in rheumatoid arthritis. Could he quote the exact figures to give some proof?

DR. WRIGHT: I am unable to give any figures for the exacerbation of rheumatoid arthritis after infection, and I am unable to give any definite figures for flare-up of psoriasis, but in childhood one does see very characteristic psoriasis of the guttate type after infection by streptococci. This is not just limited to streptococcal infection, however. The observation has never been put on a statistical basis as far as I know.

Lien entre le syndrome de Reiter et l'arthrite psoriasique

RÉSUMÉ

Parmi tous nos cas d'arthrite psoriasique nous en avons choisi douze pour les décrire minutieusement. Un d'entre eux semble présenter un exemple de coïncidence du psoriasis et de la maladie de Reiter. Les onze autres montrent l'existence d'un lien intime entre l'"arthrite psoriasique" et le "syndrome de Reiter". Ces malades présentaient des lesions de kératodermie blennorragique et des manifestations du psoriasis sur d'autres parties du corps. Le rapport temporel entre ces faits indique qu'il ne s'agit pas ici d'une liaison fortuite. La similarité de certaines formes du psoriasis et de la kératodermie blennorragique est démontrée cliniquement et histologiquement. La grande fréquence des manifestations oculaires et l'implication de l'articulation sacro-iliaque soulignent l'absence d'une ligne de démarcation entre le syndrome de Reiter et l'arthrite psoriasique. On discute l'importance de ces observations du point de vue étiologique.

\section{Conexión entre el sindrome de Reiter y la artritis psoriásica}

\section{SUMARIO}

Entre todos nuestros casos de artritis psoriásica hemos escogido doce para describirlos detalladamente. Uno de ellos parece presentar un ejemplo de coincidencia de la psoríasis y de la enfermedad de Reiter. Las demás once muestran una conexión estrecha entre la "artritis psoriásica" y el "síndrome de Reiter". Estos enfermos presentaban lesiones de queratodermia blenorrágica y manifestaciones de psoríasis en otras partes del cuerpo. El tiempo de ocurrencia de estos fenómenos indica que la relación no es puramente fortuita. La similaridad de ciertas formas de psoríasis y de queratodermia blenorrágica se ve comprobada clínica e histológicamente. $\mathrm{La}$ gran frecuencia de manifestaciones oculares y la implicación de la articulación sacro-iliaca destacan la ausencia de una línea de demarcación entre el síndrome de Reiter y la artritis psoriásica. Se discute la importancia de estas observaciones desde el punto de vista etiológico. 